\title{
Insights on the apparel needs and limitations for athletes with disabilities: the design of wheelchair rugby sports-wear
}

\author{
Sara Bragança ${ }^{a,}{ }^{*}$, Ignacio Castellucci ${ }^{b}$, Simeon Gill ${ }^{c}$, Pascal Matthias ${ }^{d}$, Miguel Carvalho ${ }^{e}$, Pedro Arezes ${ }^{f}$ \\ a Research and Innovation, Southampton Solent University, Southampton, United Kingdom \\ ${ }^{b}$ Escuela de Kinesiología, Facultad de Medicina, Universidad de Valparaíso, Valparaíso, Chile \\ 'School of Materials, University of Manchester, Manchester, United Kingdom \\ ${ }^{d}$ School of Art, Design \& Fashion, Southampton Solent University, Southampton, United Kingdom \\ ${ }^{\mathrm{e}}$ Department of Textile Engineering, University of Minho, Guimarães, Portugal \\ ${ }^{f}$ Department of Production and Systems, University of Minho, Guimarães, Portugal
}

\begin{abstract}
Wheelchair rugby is a sport that has been gaining popularity with athletes with disabilities. However, as it is relatively new and not played by the masses, market specific sports-wear is not available for this sport, which impacts directly on performance and clothing satisfaction of the athletes. Therefore, the main objective of this research was to identify the problems that wheelchair rugby players face with the sports-wear they use for playing the game. The data was collected using a focus group and a questionnaire with 61 wheelchair rugby players in the United Kingdom. Based on their suggestions, on the team expertise, and on the literature, a set of design recommendations was proposed for the upper body garments (tops), lower body garments (bottoms), and gloves. The results demonstrated that the gloves currently available negatively impact on players' ability to participate with satisfactory levels of protection and comfort. Moreover, tops and bottoms also present issues, mainly in the fit and ability to regulate the core body temperature. Hence, the recommendations proposed can provide designers with key information on the specific sports-wear requirements and allow them to design and develop products that can satisfy real needs of specific end-users. This paper intends to raise awareness of the needs of sports-wear for those playing wheelchair rugby and promote the inclusivity of athletes with disabilities.
\end{abstract}

Keywords: inclusive design; sports-wear; wheelchair rugby

\section{Introduction}

Environments and products that are adapted to wheelchair users' needs facilitate their interaction with the surroundings and promote better mobility, accessibility and comfort (Kratz et al. 1997). Clothing for people with some kind of disability is a topic that has been explored, but not in a manner that encompases all users - especially when it comes to very niche markets, like sports-wear. According to Curteza et al. (2014) clothing for people with disabilities can be classified as functional clothing and thus, should be developed to enhance the users' quality of life. The authors state that the design of these functional garments should take into consideration several scientific and technical domains (e.g. medicine, biotechnology, nanotechnology, physics, computing) in order to meet the intricate and complex requirements of the users.

The basic information designers use to create products should be derived from the real end-users, to assure that their real needs are being met and the problems are being solved. This is a more challenging way of creating novel solutions but it optimizes commercial success (Bruseberg \& McDonagh-Philp 2001). Many designers see design for disability as part of engineering and human factors (Pullin 2009). The human factors and ergonomics hierarchical approach to design gives preference to environmental design to fit the human; selecting or training people to fit the environment is only an option when there is no other alternative (Hignett 2013).

The psychological aspect of clothing should also be considered, as apparel and fashion can be regarded as an expression of self-esteem (Shim \& Bickle 1994; Fowler 1999). This is especially important for wheelchair users as assistive technologies, such as wheelchairs, often act as symbols of stigma, i.e. the social interactions created when people are thought not to meet expectations of "normal" (Elliott et al. 1982; Bispo \& Branco 2008; Carrington et al. 2014). Shinohara and Wobbrock (2011) suggest that these issues of perception and social acceptance can be mitigated if people with disabilities use mass-market products that support inclusivity. Wheelchair users have special requirements that 
common clothing does not satisfy, however, there are not many clothing brands that are dedicated to this segment of the population. In fact, some of these clothes are designed taking in consideration the measurements and body shape of able-bodied people in the sitting position (which, according to Kozey and Das (2004), are significantly different). This situation causes the clothes not to fit these specific users properly, since they do not fit into the existent size systems due to the differences in their body shape and size (Thorén 1996). As such, many wheelchair users consider that obtaining suitable clothing is a very difficult task (Chang et al. 2009). Clothing design problems create barriers in community participation and reduce the social inclusion, which might cause wheelchair users to miss out on important and everyday life events, due to clothing-related problems (Kabel et al. 2017). Nonetheless, the clothing items for this population should also be aesthetically pleasing, comfortable to wear, practical, and easy to put on and take off (Clulow 1974). It is very important that the clothes do not cause pain or discomfort.

There are several characteristics that should be present when designing clothing for people with disabilities. By resorting to focus groups, interviews, and questionnaires, some authors defined specific wheelchair users' needs and requirements. Table 1, which is based on the studies of Curteza et al. (2014), Lucero-Duarte et al. (2012), and Gonzalez et al. (2012), identifies these characteristics, divided into general considerations, characteristics of the upper body garments, characteristics of the lower body garments, and characteristics of the materials used.

Table 1. Necessary characteristics to be present on clothing for people with disabilities (based on Curteza et al. (2014), Lucero-Duarte et al. (2012), and Gonzalez et al. (2012))

\begin{tabular}{|c|c|c|}
\hline $\begin{array}{l}\text { General } \\
\text { characteristics }\end{array}$ & $\begin{array}{l}\text { - Be aesthetically pleasing } \\
\text { - Provide safety } \\
\text { - Be beneficial from a physical and } \\
\text { psychological point of view } \\
\text { - Help to socially integrate } \\
\text { - Provide moral and psychological comfort } \\
\text { - Allow dress and undress independently }\end{array}$ & $\begin{array}{l}\text { - Allow to visit the toilet independently } \\
\text { - Provide freedom of movements } \\
\text { - Have easy fastening systems (zips, Velcro and } \\
\text { elastic bands) } \\
\text { - Have specific openings to facilitate the put on } \\
\text { and take off processes } \\
\text { - Avoid friction between clothes and chair }\end{array}$ \\
\hline Upper body & $\begin{array}{l}\text { - Allow maximum use of chest and upper limbs } \\
\text { - Have increased space in back and sleeves } \\
\text { - Avoid exposure of the back areas }\end{array}$ & $\begin{array}{l}\text { - Be loose fitting in neck, chest, and abdomen } \\
\text { - Have longer lengths at the back of shirts, } \\
\text { sweaters, jackets and coats }\end{array}$ \\
\hline Lower body & $\begin{array}{l}\text { - Have increased body rise in the back } \\
\text { - Have decreased body rise in the front } \\
\text { - Be adjusted to the leg length } \\
\text { - Have longer lengths at legs } \\
\text { - Be loose fitting in buttocks and legs }\end{array}$ & $\begin{array}{l}\text { - Avoid accumulation of excess fabric in the } \\
\text { stomach area } \\
\text { - Avoid thick and hard seams, especially in } \\
\text { areas exposed to high pressures (i.e. back and } \\
\text { buttocks) }\end{array}$ \\
\hline Materials & $\begin{array}{l}\text { - Have low levels of electrostatic charge } \\
\text { - Be absorbent } \\
\text { - Be durable and resistant } \\
\text { - Be easy to maintain and clean } \\
\text { - Assure adequate thermal isolation } \\
\text { - Protect against hot and cold environments } \\
\text { - Assure moisture management in the areas } \\
\text { that sweat the most (buttocks, chest, dorsal, } \\
\text { lumbar, neck and abdomen) }\end{array}$ & $\begin{array}{l}\text { - Assure the minimum body odour retention } \\
\text { (use of natural fibres and/or anti-bacterial } \\
\text { treatment/ finishing) } \\
\text { - Have increase cloth durability in areas subject } \\
\text { to friction }\end{array}$ \\
\hline
\end{tabular}

Sports-wear is a specialist segment of the clothing industry that should also promote the inclusivity of people with disabilities and take into consideration user-centred design principles. In the sports-wear field, users search for comfort, quality, durability, and style, but comfort and fit are presumably the two most important features in this type of clothing (Fowler 1999). Kratz et al. (1997) present the findings of an experiment that compared the wheelchair users' experience of wearing specially adapted clothes and non-adapted clothes for some sports. Their study found that there was an overall positive significant difference in comfort when the participants were wearing the adapted clothes. The authors finish by saying that further studies are needed to enhance the sports experience within the wheelchair users' community. A more recent preliminary study also showed that there is a lack of availability of sports-wear for disability sports, which compromises the athletes' satisfaction, comfort and performance, giving the premise of the need to act and develop more specialized garments to satisfy this population (Braganca et al. 2018).

Wheelchair Rugby, also called quad rugby or murder ball, is a relatively new sport that was designed as a team sport for male and female athletes with a disability (even though many non-disabled people are also participating). According to the International Wheelchair Rugby Federation (IWRF 2015) the aim of the sport is to score goals by crossing the opposing team's goal line while in possession of the ball - the team scoring the most goals by the end of the game is 
declared the winner. This sport has few similarities with traditional rugby, it looks more like basketball without a basketball hoop and is becoming increasing popular even amongst nations that are not recognised as "rugby nations" (Kell et al. 2008). As in many other sports, athletes are always looking to improve their performance. In wheelchair rugby, the athletes' performance is influenced by both individual components - acceleration, manoeuvrability, movement accuracy - and team components - combination of individual components to score points for the team (Chua 2013). Evaluating athletes' performance is crucial for both coaches and athletes, as it allows for better planning of the training session to improve athletes' weaknesses and for a continuous improvement of the athlete and the wheelchair-user interface (Chua 2013; Sasaki et al. 2008; Usma-Alvarez et al. 2010).

The purpose of this paper is to identify the problems that wheelchair rugby users have with the sports-wear they use for playing the game. Additionally, this paper presents a set of design recommendations that can be used by designers to create new sport-specific garments, specifically for three important items of wheelchair rugby sports-wear: tops, bottoms and gloves.

\section{Methodology}

Sixty-one wheelchair rugby athletes, representing approximately $27 \%$ of this population (GBWR 2016), participated in this study. This study followed the three-step methodology described in Figure 1. This was an incremental process, in which every stage introduces new practical and theoretical knowledge. The stages are connected to each other, which means that the knowledge and information of previous stages are considered as acquired and are the bases for further developments. Each stage had as an input: (i) practical knowledge of the team members; (ii) information found in relevant literature; and (iii) knowledge from the previous stage(s) (except for 1. Focus group). Regarding the literature, a non-exhaustive search was conducted together with the analysis of the bibliographic references of the selected articles.

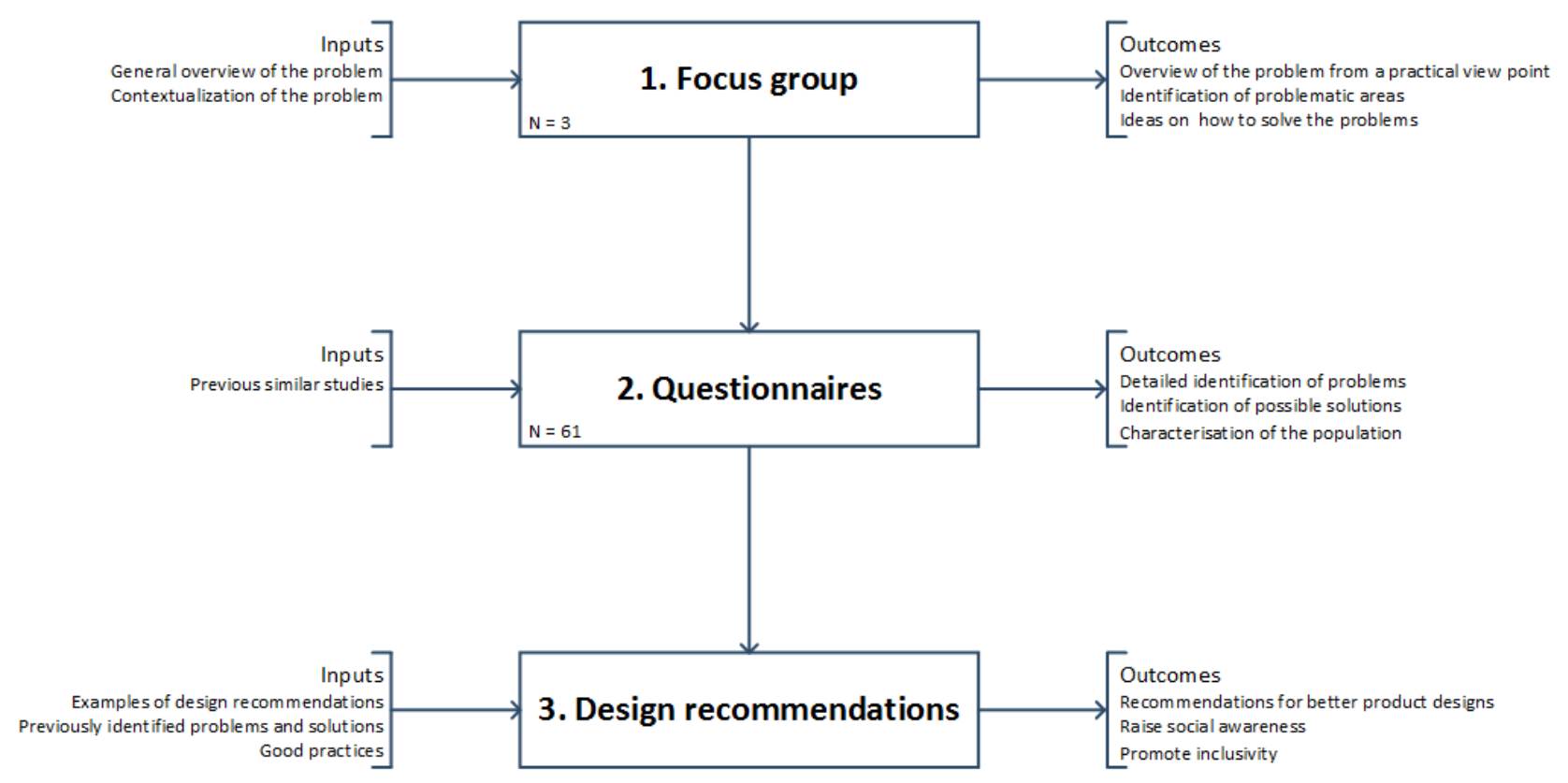

Figure 1. Methodology of the study.

Data was collected using a mixed-method approach - focus group and questionnaire. Both these data collection methodologies were used to assess the satisfaction of the athletes towards the items of sports-wear they use during the training and competition of wheelchair rugby. Furthermore, these techniques also served to identify current problems with the sports-wear and possible solutions that would satisfy the users' needs. Both the focus group and the questionnaire were previously approved by the ethics committee of the host university and accorded with the requirements of the Helsinki Declaration. Design recommendations were proposed based on the results of the focus group and the questionnaires. Relevant information from previous studies was also used to define these recommendations.

The following sub-sections describe in more detail the procedures in each stage. 


\subsection{Focus group}

The focus group was a preliminary study that served not only as a source of information, but also as a basis to later develop the questionnaire. Three of the 61 athletes participated in the focus group (they were part of the Solent Sharks team). The focus group allowed a general overview about the current situation of the sports-wear wheelchair rugby athletes' use when playing. It was conducted at the host university, where one of the researchers involved in the project moderated the session. The session was recorded on video, to which the participants agree upon by signing a consent form for video recording. Additionally, all the participants also signed a consent form that stated they agreed to participate in the study.

The moderator-researcher followed a semi-structured script that contained a set of 14 questions (see Appendix 1). The questions were formulated so that it was possible to have a general idea about several issues (e.g. fit, comfort, aesthetics, materials, and wearable technologies) and potential problems that exist related to the sport-wear used by the athletes. Additionally, the athletes were also asked to give some suggestions regarding the issues they would like to see changed. During the session, the questions were projected on a screen (as a Microsoft PowerPoint presentation) to ease the understanding of what was being asked. The participants were encouraged to speak freely. However, each participant was advised to provide at least one comment for each question. The whole session lasted approximately 1 hour and 30 minutes.

The focus group was transcribed as soon as possible to develop the questionnaire. After the transcription, the focus group contents were coded and analysed using the qualitative data analysis software MAXQDA (Standard 12.3.1, 19952017, VERBI GmbH Berlin), allowing a prompt extraction of the relevant results and insights.

\subsection{Questionnaires}

The questionnaire followed the focus group. It was launched in September 2016 and remained open until December 2016. The questionnaire was specifically designed for the purpose of this project - the questions were developed based on the outcomes of the focus group but also based on issues identified in the literature (from questionnaires employed in past relevant studies - (Wang et al. 2014; Howe 2012; Wu et al. 2011; Çivitci 2004; Wu \& Williams 2001) and on discussions between the partners of this project. The questionnaire was prepared using the Survey Monkey online tool, which generated a link that was shared among the team athletes by the university's sports manager.

This questionnaire was answered anonymously and included diverse types of questions - demographic, dichotomous, multiple choice, and open-ended - that intended to represent, in the best way possible, the opinions of the athletes regarding the items of sports-wear they usually use. It was composed of 30 questions that were structured in nine different sections (see Appendix 2).

Many questions used subjective rating scales (e.g. very convenient; convenient; normal; slightly inconvenient; very inconvenient) so that the athletes could indicate their satisfaction/dissatisfaction with the sports-wear. However, and most importantly, there were many open ended questions, to leave space for the athletes to freely describe the specific items of sports-wear, or their characteristics, they are most (di)satisfied with and the issues they would like to see addressed. One the one hand, this gives the athletes an opportunity to say what would be the ideal scenario that would address the current gap and fulfil their needs. On the other hand, this helps researchers and designers to understand the users' needs so that better products can be developed.

The analysis of the questionnaire used descriptive statistics and no other more exhaustive statistical tests, as the main purpose of the questionnaire was to have a clear idea of the current situation of the wheelchair rugby sports-wear.

\subsection{Design recommendations}

After the collection of all relevant data from the focus group and questionnaire, a set of design recommendations was proposed for three of the most important items of the sports-wear-tops; bottoms; and gloves. The solutions presented in this study were not only based on ideas presented by the athletes but also on a literature search and on the expertise of the researchers involved. The information provided by the athletes during the focus group and on the open-ended questions of the questionnaire allowed the extrapolation of potential and partial solutions to the problems identified.

The design recommendations were divided in four different categories that represent distinct types of concerns: (i) fit and comfort; (ii) safety; (iii) materials; and (iv) special features. 


\section{Results}

\subsection{Focus group}

The three participants of the focus group demonstrated much interest in having garments specialised for use in wheelchair rugby. They believe that there is a lot of scope for innovation in this area, as at this moment there is nothing specific for the sport - "Wheelchair rugby is in dark ages for clothing". They highlighted that it is possible to find a great variety of body shapes and sizes among athletes. This means that these participants cannot be seen as a representing the whole population, but are a distinct groups of athletes.

The athletes mentioned that they have to use garments designed for able-bodied people and that each one of them has to try to find their own way of getting the garments to work (i.e. fit and perform) and be comfortable. It is important that the garments are comfortable for all-day wear because during competition season, the athletes may have more than one game a day. As such, they agreed that there is a need for these specialized garments, which would help them perform better.

"At the Paralympic level it is this incremental gain that makes a difference. If you are more comfortable in your chair, you can play $2 \%$ better, and that may be enough to win or lose a game" [Athlete 1]

During the focus group a lot of discussion was given to three topics: gloves; trousers; and bespoke items. More detail about what has been said about this topics is given in the following subsections. In turn, not a lot has been said about the upper body garments. The athletes emphasised that having freedom of movement is important and, as the cut and design of the tops is standard, there is not much give in the fabric. Hence, they suggested that having stretch within the back would be beneficial.

\subsubsection{Gloves}

During this focus group a lot of attention was given to the gloves. According to these three players, the gloves are the main problem with their sports-wear. One of the athletes affirmed that "If my gloves don't work, it massively impacts the game" and the other "Gloves are a focal point, and that item alone could be a game changer". The participants said that the major problem with the gloves is that they are not sport-specific, which means they are not adapted to the sport's need. As such, athletes have to use different types of gloves ("I use cold storage gloves (...) a lot of guys wear gardening gloves or building gloves") and use tape to secure them. This process, besides being inconvenient and time consuming (it cannot be done individually, someone else has to tape the gloves for them), it involves significant costs too - one of the athletes mentioned that "I must use 300 roles of tape a year - a lot of money is spent on tape". Nonetheless, it seems like this is a sport-specific problem. It was said that the rims on the wheelchair-basketball wheelchair are smooth and metallic, whereas in wheelchair-rugby normally the wheels are plasticised so they provide extra grip.

"For me, the difficulty is not pushing forward. Pushing forward sort of pushes the gloves on. It's when you stop and break that the flow of the wheel versus your arm pushes the gloves off. (...) So, if I could secure the gloves around the wrist and if they had a durable sticky palm, that would be optimal." [Athlete 3]

\subsubsection{Trousers and other bottoms}

The trousers were also another item that was more thoroughly discussed. The athletes showed interest in having a solution that is robust and tough, but light and breathable at the same time. One of the athletes mentioned "For $a$ wheelchair user like myself, who can't put trousers on normally, something robust that you can pull up whilst lying on a bed would be great. However, you want them to be tough but you also want them to be light".

Breathability is also regarded as a key issue because, due to the impairments of some athletes, keeping cool and regulating the body temperature is challenging. Tightness and bagginess are also important aspects in the trousers. When too tight, the trousers can be very uncomfortable: "If my trousers are really tight, then it's a real problem and it will affect my performance". On the other hand, when too loose, they can get caught on the wheels and cause accidents.

Again, the cut of the trousers is not adapted to these athletes' body shape and size. This causes the lower back to be visible, which besides being uncomfortable is also aesthetically unpleasing. Hence, they suggested that the trousers should have a higher rise on the back. Nonetheless, they also adverse to stitching in the back of the garment, which requires careful consideration. 
"I'm a permanent wheelchair user and I find that when I sit down and try to put on normal trousers, they are good for standing but with the sort of body shape that I have, I tend to find that the lower back is visible" [Athlete 2]

Lastly, one of the athletes also mentioned that with the trousers they are currently using, they have to wear underwear. This might be a problem for this population because it gives them another layer of clothing that is just causing them to increase the body temperature, which is hard to control ("If I had track suit bottoms that are more reliable and had a decent stitching, then I could lose those [the underwear], which again is just a small amount of heat that I wouldn't have to worry with").

\subsubsection{Bespoke items}

The opportunity of having bespoke items of sports-wear seems to be something that the athletes are really interested in. They believe that it would be a good way of satisfying each one's personal needs ("Anyone in the squad would be raising money for them [bespoke items] if they knew that it was going to give them an edge"). However, they also highlighted the fact that high costs of these specialised equipment (alongside other specialised accessories like prosthetics) might be a barrier to participation, especially for beginners. Nonetheless, some of the athletes would be willing to spend more money if they were assured that the garments are sport-specific and would perform better than the others.

"Nobody is the same, so being able to have a bespoke fit for an individual, being able to make one garment for one person, would cost more money than doing 12 standard garments for the same body shape. But, we are dealing with, even in this room, very different types of people, so I think that that bespoke individuality would be really good." [Athlete 1]

\subsection{Questionnaires}

The 61 non-professional wheelchair rugby athletes that participated in the questionnaire played for 21 teams/clubs across the United Kingdom. Table 2 shows the distribution of the athletes through the teams/clubs.

Table 2. Distribution of the athletes through teams/clubs.

\begin{tabular}{lll}
\hline Team & Location & No. of athletes \\
\hline Caledonian Crushers & Glasgow & 8 \\
\hline Canterbury Hellfire & Canterbury & 3 \\
\hline Dorset Destroyers & Poole & 1 \\
\hline Dundee Dragons & Dundee & 2 \\
\hline Glasgow Panthers & Glasgow & 1 \\
\hline Gloucester Wheelchair Rugby & Gloucester & 1 \\
\hline Gravesend Dynamite & Gravesend & 1 \\
\hline Halifax Wheelchair Rugby & Halifax & 1 \\
\hline Hereford Harriers & Hereford & 1 \\
\hline Liverpool Lions & Liverpool & 2 \\
\hline London Wheelchair Rugby & London & 7 \\
\hline North East Bulls & Sedgefield & 1 \\
\hline Ospreys & Cardiff & 1 \\
\hline Solent Sharks & Southampton & 9 \\
\hline Stoke Mandeville Maulers & Aylesbury & 6 \\
\hline The Argonauts & Dartford & 1 \\
\hline West Coast Burn & Southport & 2 \\
\hline West Coast Crash & Southport & 2 \\
\hline West Country Hawks & Plymouth & 2 \\
\hline Woodbridge Wheeled Warriors & Woodbridge & 2 \\
\hline Yorkshire Lions & Featherstone & 7 \\
\hline & & 2 \\
\hline
\end{tabular}


The participants of this study all had different types of impairments that conditioned them to use a wheelchair. Some examples of reported impairments include: amputation, brain injury, cerebral palsy, multiple sclerosis, muscle dystrophy, spina bifida, and spinal cord injury. Table 3 shows some basic information that characterises the sample sample size, age range, gender, and number of years playing the sport.

Table 3. Characterisation of the sample.

\begin{tabular}{llll}
\hline Variable & Categories & $\mathbf{N}$ & $\mathbf{\%}$ \\
\hline Frequency in each age group & $18-30$ & 23 & $37.7 \%$ \\
& $31-40$ & 12 & $19.7 \%$ \\
& $41-50$ & 17 & $27.9 \%$ \\
& $51-60$ & 7 & $11.5 \%$ \\
Gender & $60+$ & 2 & $3.3 \%$ \\
& Male & 54 & $88.5 \%$ \\
\hline
\end{tabular}

Of the 61 athletes questioned, some have been playing the sport for a long time (up to 33 years), while others have just joined a team (have been playing only for two months). Still, most of them have been playing the sport from 3 to 4 years (approximately 37\%). When asked, most athletes stated that the main reason they play wheelchair rugby is for social aspects and for rehabilitation purposes.

Regarding the sports-wear used during training and competition, the majority of the athletes stated they use sportsspecific t-shirts and shorts/trousers that are meant for other sports (e.g. basketball, football, etc.), as there are no garments available for this specific sport. Only three athletes said they use bespoke t-shirts and shorts/trousers specific for wheelchair users.

Approximately $92 \%$ of the participants stated that they use the garments until they become worn out or damaged, not because they are out of fashion. This may also indicate that functionality is preferred over aesthetics by this population. This is also confirmed by the fact that $33.4 \%$ of the athletes needs some kind of help to put on and to take off the garments.

\subsubsection{User satisfaction and modifications to sports-wear}

Most athletes indicated they are fairly satisfied with the sports-wear they are currently using. Nonetheless, for $30 \%$ of the participants the dissatisfaction was high (19.3\% more or less satisfied; $8.8 \%$ not very satisfied; $1.8 \%$ very unsatisfied). When questioned about the causes of the dissatisfaction, most participants identified fit and temperature as the main reasons (Figure 2 [a]). In terms of the specific items of sports-wear that cause dissatisfaction, the most troublesome are the gloves, followed by the trousers and sleeveless tops and vests (Figure 2 [b]).

$100 \%$

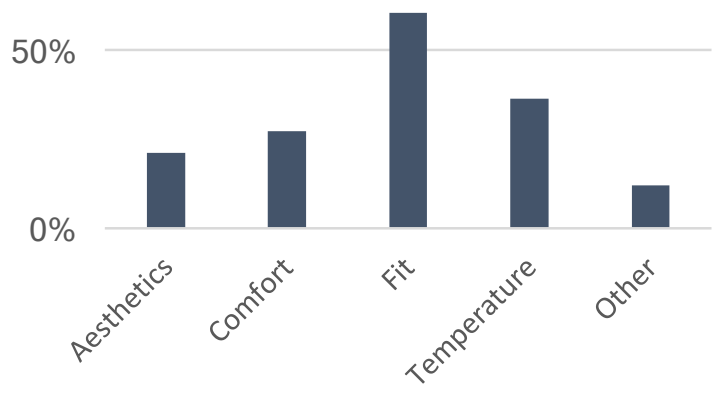

$100 \%$

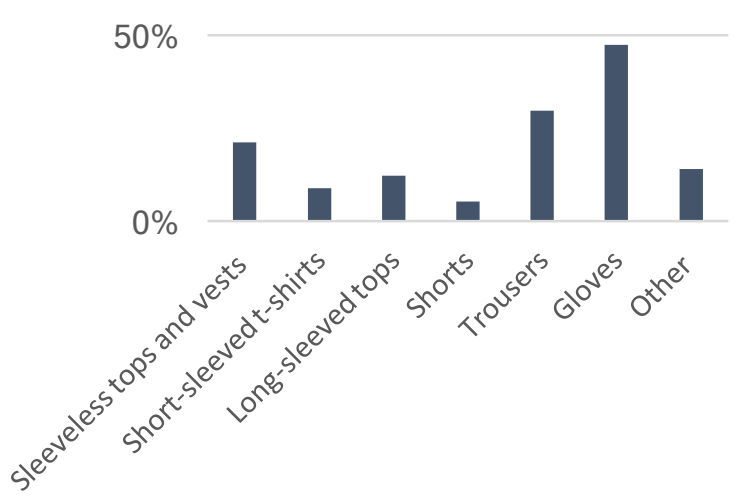

[b]

[a]

Figure 2. Distribution of the frequency of dissatisfaction: (a) causes of dissatisfaction; (b) dissatisfaction towards specific items of sports-wear. 
The problems with the fit are also reflected in the next question, about the modifications athletes have to make to the ready-to-wear sports-wear so that their impairment is better accommodated. A few examples of what has been said by the participants are as follows:

\section{"I cut the length of the trousers due to my leg size"}

"I have an above knee amputation so I have to tuck one leg in the waistband, which is uncomfortable"

"I have to wear my tracksuit bottoms as I can't get any to fit me - I'm 13 but have to use 5 year old clothes"

"I put a hole in my leggings so I can empty my leg bag through my leggings without taking them off"

"I add leather patches on shoulder to grip the wheels"

"I add rubber and glue to my gloves"

"Rubber patches added to palm of gloves"

"The gloves don't fit too well so I have someone stitch part of gloves on the top to pull in and make gloves fit little and ring finger better and more comfortably"

"The gloves need to be taped on"

\subsubsection{Choosing and buying sports-wear}

When the athletes go to buy new sports garments for wheelchair rugby, there are certain features that are preferred. Fit is the one feature that makes them choose one garment over the others. Likewise, price and comfort are also important characteristics that athletes look out for. Figure 3 depicts a word cloud with main features mentioned by the athletes (the bigger the size of the word, the more often it was mentioned in the questionnaire).

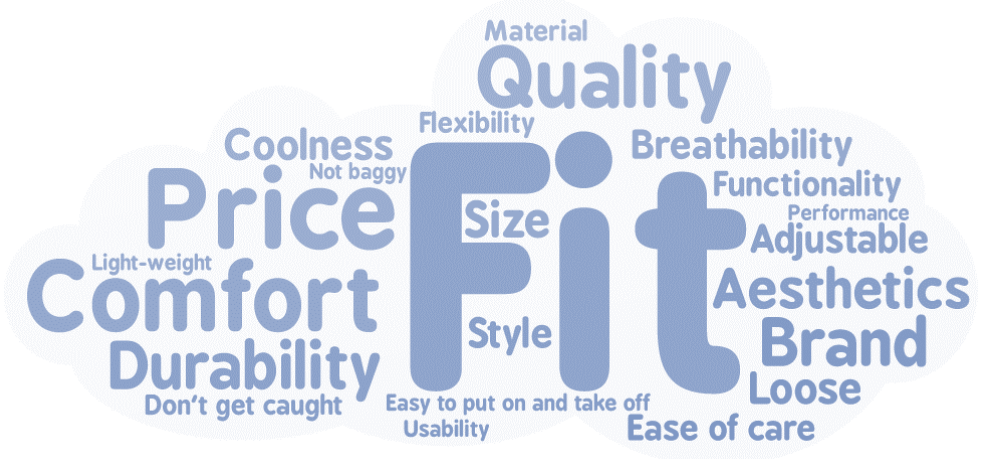

Figure 3. Word cloud for the preferred features when buying sports-wear.

In line with the previous question, the athletes were asked to specify the characteristics they value the most for each part of their sports-wear, i.e., sleeveless tops and vests; short-sleeved t-shirts; long-sleeved tops; shorts; trousers; and gloves (Figure 4). For every garment, functionality and comfort were reported as the most important features. It is crucial to note that performance was the most important feature, only for gloves. 


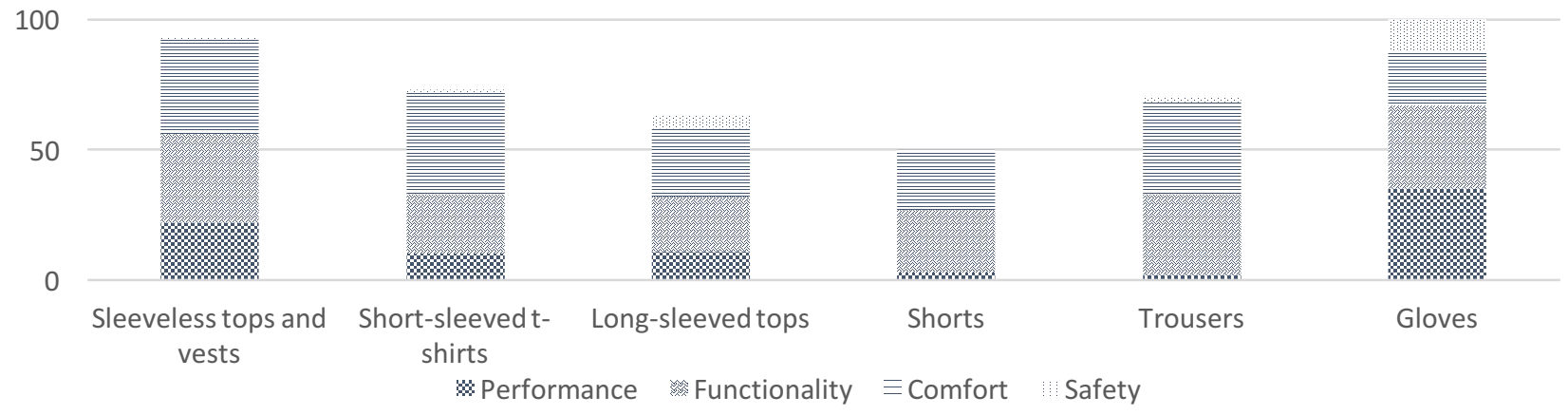

Figure 4. Distribution of preferred features according to garments.

Almost $80 \%$ of the participants confirmed that sports-wear stores do not offer a wide variety of garments specific for wheelchair users. When asked how that makes them feel, the following examples reflect the participants' feelings:

"Annoyed", "Disappointed"; "Frustrated"; "Inconvenient"; "Marginalised" ; "Segregated" ; "Unhappy"

"Like I am being penalised for not fitting the normal clothing style"

"Under appreciated as an athlete"

"It makes me feel sad because you could be stopped for doing sport because you cannot get the equipment you need from sports-wear shops"

The available ready-to-wear garments usually present some problems for these athletes. The most common problem encountered is that the garments do not fit the athletes' body shape and size. It seems like for most parts of the body the available clothes are loose. This happens especially in the calves, chest, hips, buttocks, crotch and thighs.

As such, when choosing and buying sports-wear, the athletes look for, at a first instance, clothes that provide good fit and comfort and then they consider price and quality. Being suitable for wheelchair users seems to be more important for the athletes than being rugby-specific. Some people buy bespoke items, however the price is what influences them the most to avoid this option.

\subsubsection{Restriction of movements caused by sports-wear}

When asked about the restriction of movements caused by sports-wear, the activities that cause the most restriction are moving the wheelchair ( $50 \%$ of the participants reported this as a problem) and throwing the ball (a problem for $14 \%$ of the participants).

The next question of the survey focused on understanding in detail the main causes of these restrictions. A few examples reported by the athletes are:

- Poor fitted clothing, whether it is too tight or too loose;

- Garments that are loose fitting impede pushing the wheelchair and can be accidently trapped on wheels and push rims;

- $\quad$ The materials of the team tops make it difficult to regulate the core body temperature;

- Gloves that are too tight or too rigid affects performance and the way the wheelchair is manoeuvred;

- Gloves that are not appropriate for this sport wear out quickly, reduce the dexterity of fingers and do not allow a good control and manoeuvrability of the wheelchair.

According to the participants, the specific areas of the body where the sports-wear causes the most restriction are the hands, followed by the shoulders; arms; waist and abdomen; and hips. Figure 5 shows the distribution of the frequency of restrictions felt in each body-part. 


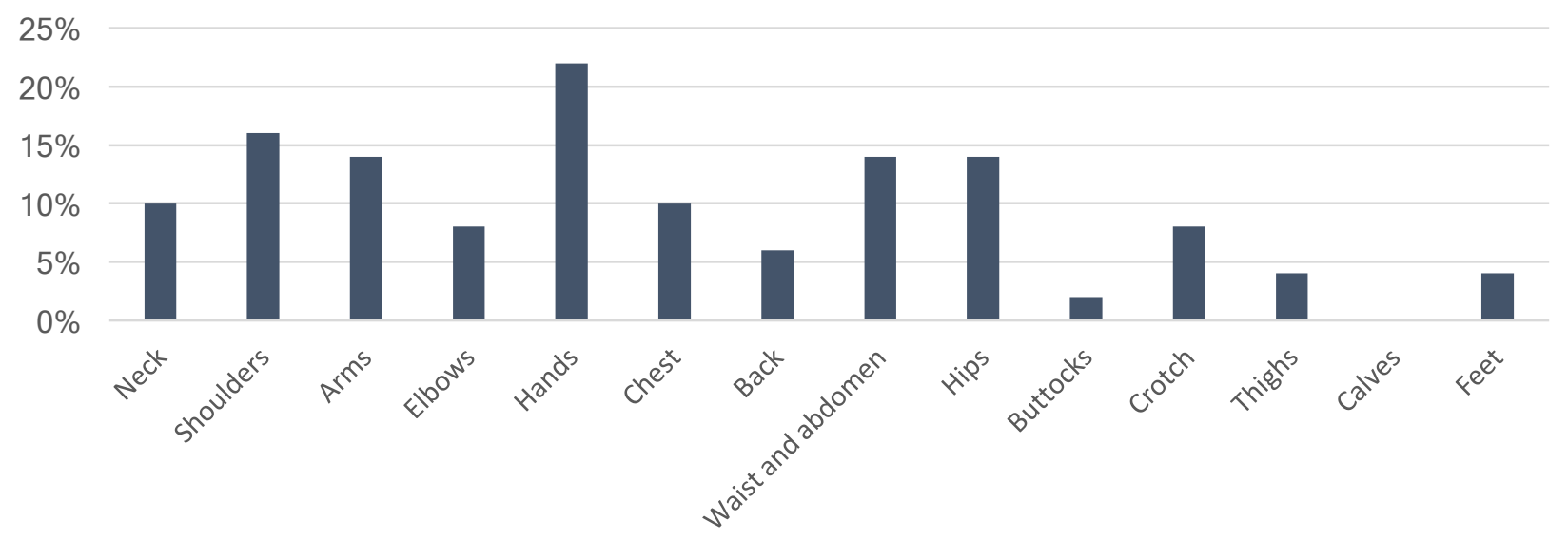

Figure 5. Distribution of the frequency of restrictions felt by body-part.

\subsubsection{Sports-wear materials and wearable technologies}

The athletes appeared to be generally satisfied with the materials the sports-wear are made of. However, $34.7 \%$ are not very satisfied with the materials. Hence, when asked what they would like to see changed, some participants suggested the following:

- Tops that can better absorb sweat;

- Use of high-performance materials, e.g. compression fabrics;

- Tougher materials that are soft and breathable at the same time;

- Durable and light gloves that ensure a good grip.

The participants were also asked to identify the most important qualities of sports-wear materials for a set of body parts. Table 4 shows the frequency of the answers for each characteristic in each body part, i.e. the response count. From the list provided it was clear that breathability and durability, followed by softness, absorbance and lightness are the most relevant features. Nonetheless, the distribution of these characteristics is not the same for every body part e.g. breathability and absorbance are more important in the chest area than in other areas like elbows and hips. Interestingly, and matching the results from the focus group and other questions in the survey, for the hands, durability, followed by breathability and resistance to tears, are the most important characteristics, which are currently not an option with the gloves the athletes use.

Table 4. Distribution of frequency of the importance of materials' features by body part.

\begin{tabular}{|c|c|c|c|c|c|c|c|c|c|c|c|}
\hline & $\frac{\pi}{0}$ & 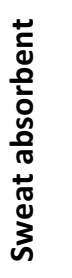 & $\begin{array}{l}\frac{0}{0} \\
\frac{0}{0} \\
\frac{5}{5} \\
\frac{\pi}{00} \\
0\end{array}$ & $\begin{array}{l}\frac{0}{0} \\
\frac{0}{0} \\
\frac{0}{0}\end{array}$ & $\begin{array}{l}\frac{\xi}{\pi} \\
\frac{\pi}{3}\end{array}$ & 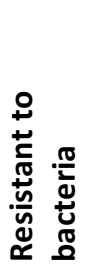 & סू & $\begin{array}{l}\frac{z}{0} \\
0 \\
+\frac{0}{3} \\
\frac{0}{3}\end{array}$ & 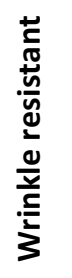 & 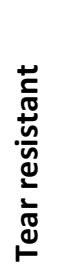 & 苛 \\
\hline Neck & 22 & 15 & 32 & 18 & 4 & 5 & 16 & 8 & 5 & 14 & 23 \\
\hline Shoulders & 15 & 17 & 29 & 19 & 5 & 5 & 11 & 7 & 4 & 12 & 20 \\
\hline Arms & 17 & 14 & 27 & 20 & 3 & 3 & 8 & 5 & 2 & 10 & 17 \\
\hline Elbows & 13 & 8 & 17 & 20 & 2 & 2 & 6 & 4 & 3 & 15 & 12 \\
\hline Hands & 12 & 11 & 21 & 31 & 4 & 5 & 9 & 5 & 1 & 21 & 12 \\
\hline Chest & 15 & 21 & 35 & 21 & 6 & 5 & 10 & 7 & 5 & 11 & 16 \\
\hline Back & 13 & 19 & 29 & 18 & 6 & 4 & 8 & 5 & 7 & 12 & 16 \\
\hline Waist and abdomen & 18 & 17 & 23 & 20 & 6 & 5 & 10 & 5 & 3 & 9 & 12 \\
\hline Hips & 19 & 14 & 24 & 16 & 4 & 7 & 10 & 6 & 3 & 9 & 15 \\
\hline Buttocks & 17 & 18 & 27 & 15 & 3 & 8 & 12 & 6 & 5 & 12 & 15 \\
\hline Crotch & 19 & 19 & 29 & 10 & 3 & 11 & 13 & 6 & 4 & 10 & 16 \\
\hline Thighs & 19 & 15 & 30 & 17 & 5 & 4 & 9 & 3 & 4 & 9 & 14 \\
\hline Calves & 18 & 11 & 25 & 13 & 6 & 3 & 6 & 5 & 1 & 5 & 12 \\
\hline Feet & 17 & 15 & 25 & 21 & 7 & 6 & 7 & 6 & 2 & 7 & 12 \\
\hline
\end{tabular}


Finally, wearable technologies were also mentioned in this questionnaire. Based on the rating average, it was possible to find out the wearables that the athletes are more interested in. From the one ranked as the most relevant to the least relevant, the results obtained were as follows: monitor heart rate; record distance; register a push; register speed; monitor skin temperature; calculate calories burnt.

\section{Discussion and design recommendations}

Based on relevant literature and on the answers gathered in the focus group and questionnaires presented in this study it was possible to define some design recommendations. These design recommendations are grouped according to the garment type (tops; bottoms; and gloves) and are presented in the following sub-sections. The design recommendations were grouped into several categories to answer to different concerns, namely fit and comfort; safety; materials; and special features.

\subsection{Tops - from sleeveless to long-sleeved shirts}

The set of design recommendations suggested for the tops, being sleeveless or long-sleeved shirts - hereon identified as $\mathrm{DR}_{\text {top }}$ and the respective number - are presented on Table 5. A brief explanation of the recommendations follows the table. Figure 6 gives a summary and visual representation of the design recommendations for the tops.

Table 5. Design recommendations for the tops

\begin{tabular}{|c|c|}
\hline $\begin{array}{l}\text { Tops } \\
\text { Problem / Need }\end{array}$ & Design Recommendation \\
\hline \multicolumn{2}{|l|}{ Fit and comfort } \\
\hline Tops are too tight and too loose in some areas & $\mathrm{DR}_{\text {top }} 1$ | Tight but not form-fitting tops \\
\hline Tops with high necks are difficult to put on & $\mathrm{DR}_{\text {top }} 2 \mid \mathrm{V}$-necked tops \\
\hline Athletes with different arm length and amputations & $\mathrm{DR}_{\text {top }} 3$ | Detachable sleeves by sections \\
\hline \multicolumn{2}{|l|}{ Safety } \\
\hline Long sleeves used for protection & $\mathrm{DR}_{\text {top }} 4 \mid$ Reinforced back of sleeves \\
\hline Loose tops get caught on wheels and push rims & $\mathrm{DR}_{\text {top }} 1 \mid$ Tight but not form-fitting tops \\
\hline \multicolumn{2}{|l|}{ Materials } \\
\hline Difficulty in regulating the core body temperature; & $\begin{array}{l}\mathrm{DR}_{\text {top }} 5 \text { | More adequate textile structure and } \\
\text { combination of materials }\end{array}$ \\
\hline Sweat is not absorbed properly & $\begin{array}{l}\mathrm{DR}_{\text {top }} 5 \text { | More adequate textile structure and } \\
\text { combination of materials }\end{array}$ \\
\hline \multicolumn{2}{|l|}{ Special features } \\
\hline Lower back is visible & $\mathrm{DR}_{\text {top }} 6$ | Longer back \\
\hline
\end{tabular}



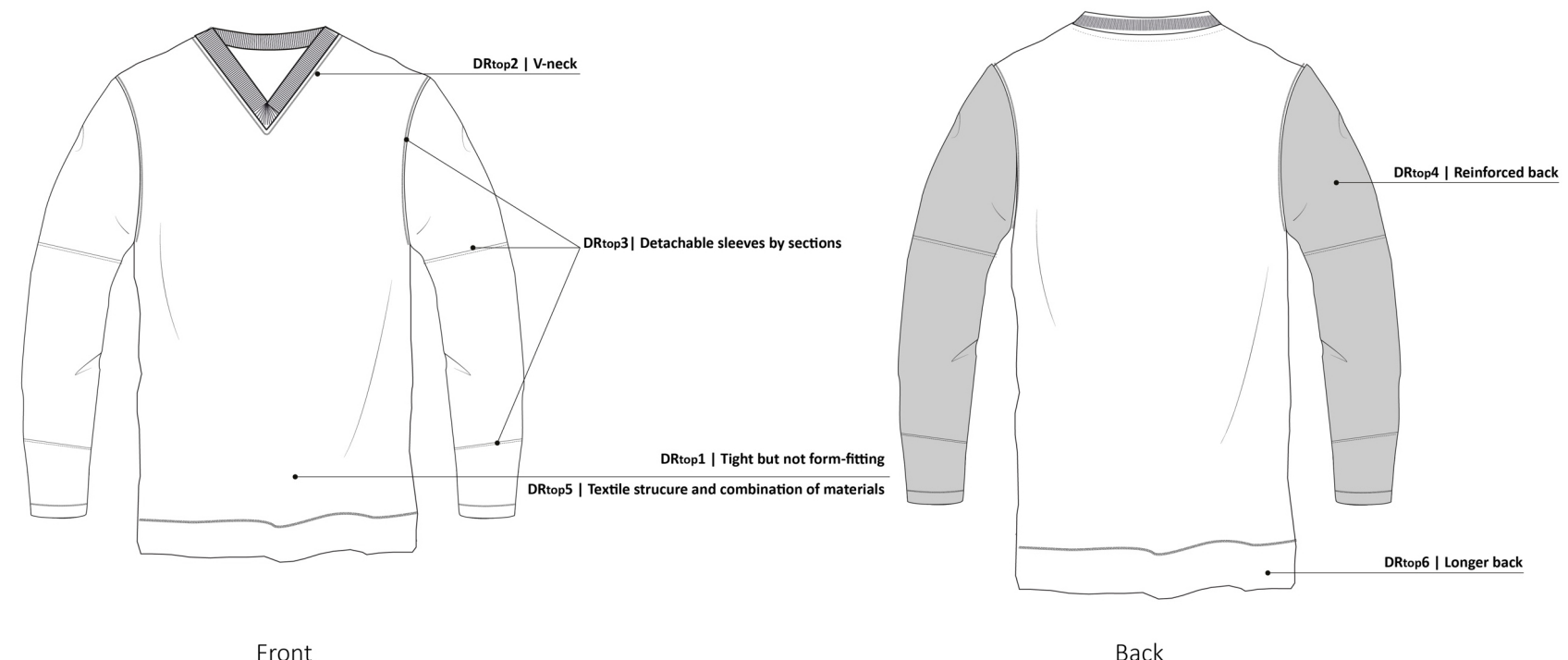

Figure 6. Summary and visual representation of the design recommendations for the tops.

DR $_{\text {top }} 1$ | Tight but not form-fitting tops | Having a tighter (but not form-fitting) fit on the tops would not only allow for an added comfort but it would also prevent the tops to get caught on wheels and push rims, improving the overall safety. Some athletes are a little self-conscious of their bodies and do not want to show every detail, hence, the tops not being form-fitting allows for this privacy. Nonetheless, designers should remember to take in consideration the body shape and size of this user population, i.e., the relevant anthropometric measurements (Bragança et al. 2017).

DR $_{\text {top }} 2$ | V-necked tops | Having a V-necked shirt increases the space available for the neck, which improves comfort and reduces the feeling of constriction.

DR $_{\text {top }} 3$ | Detachable sleeves by sections | Some of these athletes have arm amputations or suffer from other conditions that affect the length of their arms. Therefore, having the possibility of detaching the whole arm, or sections of it, would make the shirt wearable and comfortable to use by all. This way, they do not need to roll up their sleeve to adjust the top to their needs. Moreover, this functionality could also be used by all the other athletes based on their particular preference - whether they want to use a sleeveless top, a t-shirt, a $3 / 4$ sleeved top or a long-sleeved top. The different sections make the product more customisable and user-friendly. The various sections could be connected using a Velcro material, which is easy to use and maintain, inexpensive and effective. It would be important to ensure that the sections can be combined together without any bulkiness or heavy seams.

$\mathbf{D R}_{\text {top }} 4$ | Reinforced back of sleeves | The back of the arms are often in contact with the wheelchair, hence the athletes tend to use a long-sleeved shirt for protection. It would be important to have a more resistant material in the back of the sleeves to protect the athletes' arms against the friction with the wheelchair during the manoeuvres performed while playing. Synthetic fibres such as polyester or polyamide could be suitable options. These fibres are typically used in areas of high abrasion (e.g. knees and elbows) as they have a higher breaking strength and are less prone to wear than natural fibres, providing an increased resistance to friction in this area (Gill \& Prendergast 2015; Wang et al. 2014; McCann 2008).

$\mathrm{DR}_{\text {top }} 5$ | More adequate textile structure and combination of materials |Spinal cord injuries tend to affect the way body core temperature is regulated. As such, it would be important for the garments to assist in this process. New sports textiles tend to use both synthetic and natural fibres to improve their performance. Cotton blended with polyamide, polypropylene or regenerated fibres would provide the garments with the ability to perform better, to have a better wicking ability, allow convection, be less absorbent and faster in drying (Özdil \& Anand 2014). These characteristics would allow for the core body temperature to be more easily maintained and the sweat absorbed properly to the exterior of the body, evaporating to the air. The relevance of mixing fibres is about not holding sweat near the body surface and moving it to the surface of the garment, therefore, the textile structure used is also relevant to develop this 
capacity. Synthetic non-absorbent fibres should be used in contact with the skin to encourage wicking whereas natural hygroscopic fibres should be used in the exterior part of the garment to encourage evaporation and cooling associated with this (Sionkowska 2011).

DR $_{\text {top }} 6$ | Longer back | Sometimes, due to the poor fit of the tops (frequently designed for able-bodied people) or due to the demands of the game, the lower back of the athletes becomes exposed and in contact with the chair. This, despite not being aesthetically pleasing and making players self-consciousness, it might also be dangerous as the rubbing of the skin against the chair might cause irritations and wounds. Hence, having a longer back on the tops would impede this from happening and still allow for the range of movement required. Whilst increasing the back of the top would provide modesty, it should not be so long that it creates bulk and possible discomfort through layering in contact with the chair.

\subsection{Bottoms - from shorts to full trousers}

The set of design recommendations suggested for the bottoms, being shorts or full trousers - hereon identified as $\mathrm{DR}_{\mathrm{bot}}$ and the respective number - are presented on Table 6. A brief explanation of the recommendations follows the table. Figure 7 gives a summary and visual representation of the design recommendations for the bottoms.

Table 6. Design recommendations for the trousers

\begin{tabular}{ll}
\hline Trousers & Design Recommendation \\
\hline Problem / Need & \\
\hline Fit and comfort & $\mathrm{DR}_{\text {bot }} 1$ | Tight but not form-fitting bottoms \\
$\mathrm{DR}_{\text {bot }}$ | Elasticated waistband
\end{tabular}




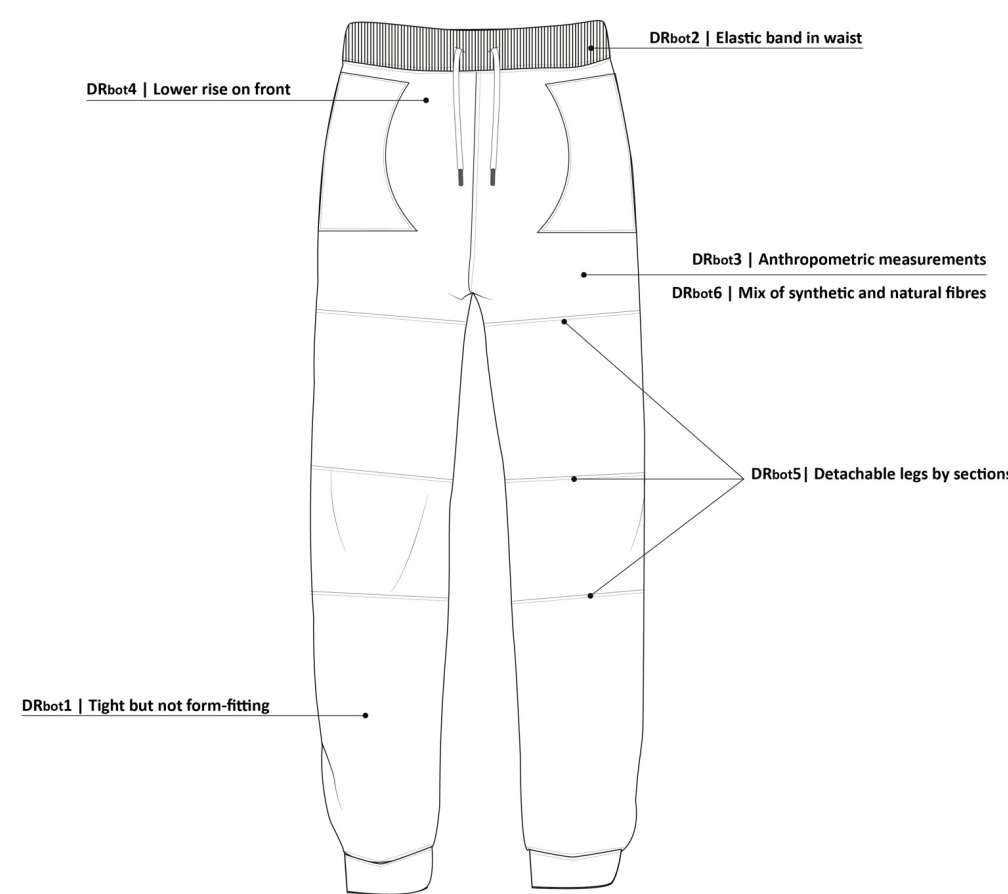

Front

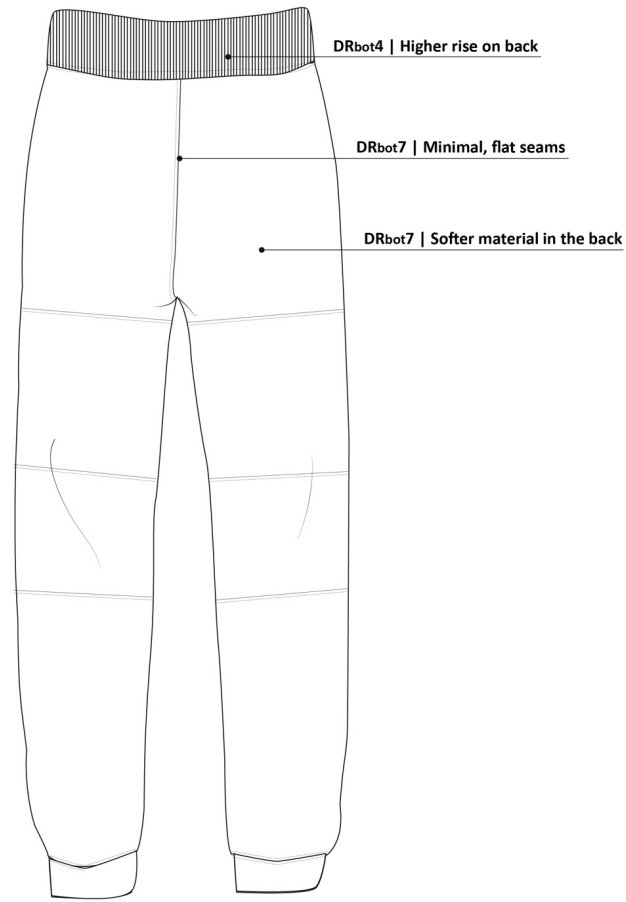

Back

Figure 7. Summary and visual representation of the design recommendations for the bottoms.

$\mathrm{DR}_{\text {bot }} 1$ | Tight but not form-fitting bottoms | The same issues as with the tops occur with the bottoms, i.e. they get caught on wheels and push rims, compromising the overall safety. Hence, by having a tighter fit of the trousers, this situation could be improved. Still, the trousers should not be too tight, not only to provide some privacy, but also because some athletes need to use leg bags, which they would like to be concealed, discrete and not visible to others.

$\mathbf{D R}_{\text {bot }} 2$ | Elasticated waistband | An elasticated band on the waist area would allow for the bottoms to be adjusted to the contour of the body, without causing too much pressure. Nonetheless, it would be important to ensure that the elastic is thick enough (about $2 \mathrm{~cm}$ wide) to spread the pressure throughout a larger area in the waist region.

DR $_{\text {bot }} 3$ I Consider population's anthropometric measurements I Considering the end-user populations anthropometric measurements would allow for the design to be adjusted to their specific body shapes and sizes (Bragança et al. 2017). It would also be important to ensure that the measurements taken reflect the actual posture of the athletes, as often measurements that are collected in a standardised posture that does not correspond to the posture they spend the most time in. Moreover, ensuring that the posture commonly assumed is properly represented will have a great impact on the pattern design, especially in areas such as the waist (where the rise should be higher on the back and lower on the front) or knees (where there usually is excess fabric accumulated on the back of the knee, causing discomfort and high pressure) (Bragança et al. 2015; Carvalho et al. 2015)

DR $_{\text {bot }} 4$ | Higher rise on back and lower rise on front | Being in the sitting position for long periods of time should imply that the clothing design is different than when standing for long periods of time (Bragança et al. 2016a; Bragança et al. 2016b). The shape of the body changes according to the posture adopted and hence, when adopting the sitting posture there is no need for the bottoms to be as high on the front, as it might cause some discomfort and pain (due to the accumulation of excess fabric), not for them to be as low on the back, as it exposes the skin (and might cause skin irritations). Therefore, the pattern design and cut should be re-adjusted, having a higher rise on the front and a lower rise on the back.

$\mathbf{D R}_{\text {bot }} 5$ | Detachable legs by sections | The same issues as with the tops occur with the bottoms, i.e. some athletes have leg amputations or suffer from other conditions, so having a customisable leg length would make this garment more comfortable to use by all. In the same line as before, this functionality is also useful for the athletes that do not 
suffer from any of these conditions but still want to personalise their bottoms according to their momentary need using shorts of full trousers. It would be important to ensure that the sections can be combined together without any bulkiness or heavy seams.

DR $_{\text {bot }} 6$ | Mix of synthetic and natural fibres | Again, the same situation that occurs for the tops also happens for the bottoms. Athletes would like to have trousers/shorts made of materials that allow them to regulate their body temperature more easily and that are resistant and light at the same time. Hence, mixing synthetic and natural fibres seems to be a good option (for more detail see $\mathrm{DR}_{\text {top }} 5$ ).

DR $_{\text {bot }} 7$ | Softer material in the back and minimal, flat seams | A softer material would be preferred, especially in the back of the bottoms since this area is the most exposed to contact with the wheelchair. Natural fibres such as cotton blended with some kind of synthetic fibre, would be a good alternative, as it would also properly absorb sweat, which also contributes to skin irritations (Özdil \& Anand 2014; Kim et al. 2008). Furthermore, the existence of thick seams has been reported as one of the main causes of the development of pressure ulcers. This hazardous effect is due to the lack of oxygenation and sanguineous circulation in the body (Hernández 2000; Carvalho et al. 2009). When parts of the garment that are in contact with both the skin and the wheelchair (especially over areas of bony protuberances) have overlapping fabric, thick seams, accessories (e.g. buttons, embellishments) there might be the occurrence of high pressure. These high levels of pressure at key points of the body, cause in many cases discomfort and, ultimately cause the development of chafes and sores (which may, in the worst case, lead to pressure ulcers). Therefore, reducing the thickness and amount of seams, especially in the back of the bottoms should be done. New technologies are providing the opportunity to engineer the garments seamlessly in areas of contact with the skin. The latest generation of hightech garments is completely free of sewn seams. Also, sewing can be replaced by bonding, which allows for close-fitting garments to be even more efficient - laser-cut edges, watertight zippers and trimming can now be compressed into a single indivisible bonded layer (Bramel 2008).

\subsection{Gloves}

Despite the fact that gloves are a major concern in wheelchair rugby there are not many studies published on this topic. Still, those available concur with this study - there are no gloves that are specific for wheelchair rugby, which causes the athletes to modify the existing ones in order to accommodate the performance requirements (Mason et al. 2009; Lutgendorf et al. 2009; Churton \& Keogh 2013).

Even the International Wheelchair Rugby Federation acknowledges that "many different types of gloves are available to choose from", however, none are sport-specific. Further, they state that "Many athletes prefer using rubber coated cotton gloves (...) because they are inexpensive and provide considerable grip to the player. Using tape to secure gloves to your wrist is a common practice and is highly recommended". Nonetheless, this information is only available on their website (IWRF 2017), the document with the International Rules for the Sport of Wheelchair Rugby (IWRF 2015) does not provide any information about gloves.

The study of (Mason et al. 2009) tried to determine the effectiveness of different glove types on mobility performance in wheelchair rugby. The authors found that the gloves performed significantly better when they were modified and adapted for the specific athletes' needs. However, they believe that this might be caused by many different reasons. Hence, they advise that further research is needed to evaluate the athletes' interaction with different types of gloves. The work of (Lutgendorf et al. 2009) also evaluated the effect of different gloves on standardized wheelchair rugby performance compared with not using gloves at all (however, the tests were done in able-bodied participants). This study lead to the conclusion that the use of different types of gloves significantly influenced performance. Nonetheless, some gloves helped the athletes to perform better than others (NFL - US National Football League - gloves were the most favourable ones, whilst multipurpose were even worse than not wearing gloves at all). In these two studies it was clear that there is a real need to develop gloves specific to this sport that fulfil the athletes specific needs and requirements.

The set of design recommendations suggested for the gloves - hereon identified as DRglo and the respective number are presented on Table 7. A brief explanation of the recommendations follows the table. Figure 8 gives a summary and visual representation of the design recommendations for the bottoms. 
Table 7. Design recommendations for the gloves

\begin{tabular}{|c|c|}
\hline \multicolumn{2}{|l|}{ Gloves } \\
\hline Problem / Need & Design Recommendation \\
\hline \multicolumn{2}{|l|}{ Fit and comfort } \\
\hline Tape around wrists to secure gloves & $\mathrm{DR}_{\text {glo }} 1 \mid$ Velcro wrap cuff \\
\hline Space for the fingers is too long & $\mathrm{DR}_{\mathrm{glo}} 2$ 2| Elastic fingertips \\
\hline Assistance needed to put on the gloves & $\mathrm{DR}_{\mathrm{glo}} 3$ | Central opening \\
\hline \multicolumn{2}{|l|}{ Safety } \\
\hline $\begin{array}{l}\text { Manoeuvring the wheelchair causes the gloves to come } \\
\text { off }\end{array}$ & $\mathrm{DR}_{\mathrm{glo}} 1 \mid$ Velcro wrap cuff \\
\hline \multicolumn{2}{|l|}{ Materials } \\
\hline Rubber and glue added to the gloves' palms & $\mathrm{DR}_{\mathrm{glo}} 4 \mid$ Palm coated with sticky material \\
\hline Gloves are not very breathable, light, not absorbent & $\begin{array}{l}\mathrm{DR}_{\text {glo }} 5 \text { | Sweat-absorbent, breathable, malleable, } \\
\text { resistant gloves }\end{array}$ \\
\hline Gloves wear out quickly & $\begin{array}{l}\mathrm{DR}_{\text {glo }} 5 \text { | Sweat-absorbent, breathable, malleable, } \\
\text { resistant gloves }\end{array}$ \\
\hline $\begin{array}{l}\text { Too tight and too rigid materials affect manoeuvrability } \\
\text { and dexterity of fingers }\end{array}$ & $\begin{array}{l}\mathrm{DR}_{\text {glo }} 5 \text { | Sweat-absorbent, breathable, malleable, } \\
\text { resistant gloves }\end{array}$ \\
\hline
\end{tabular}

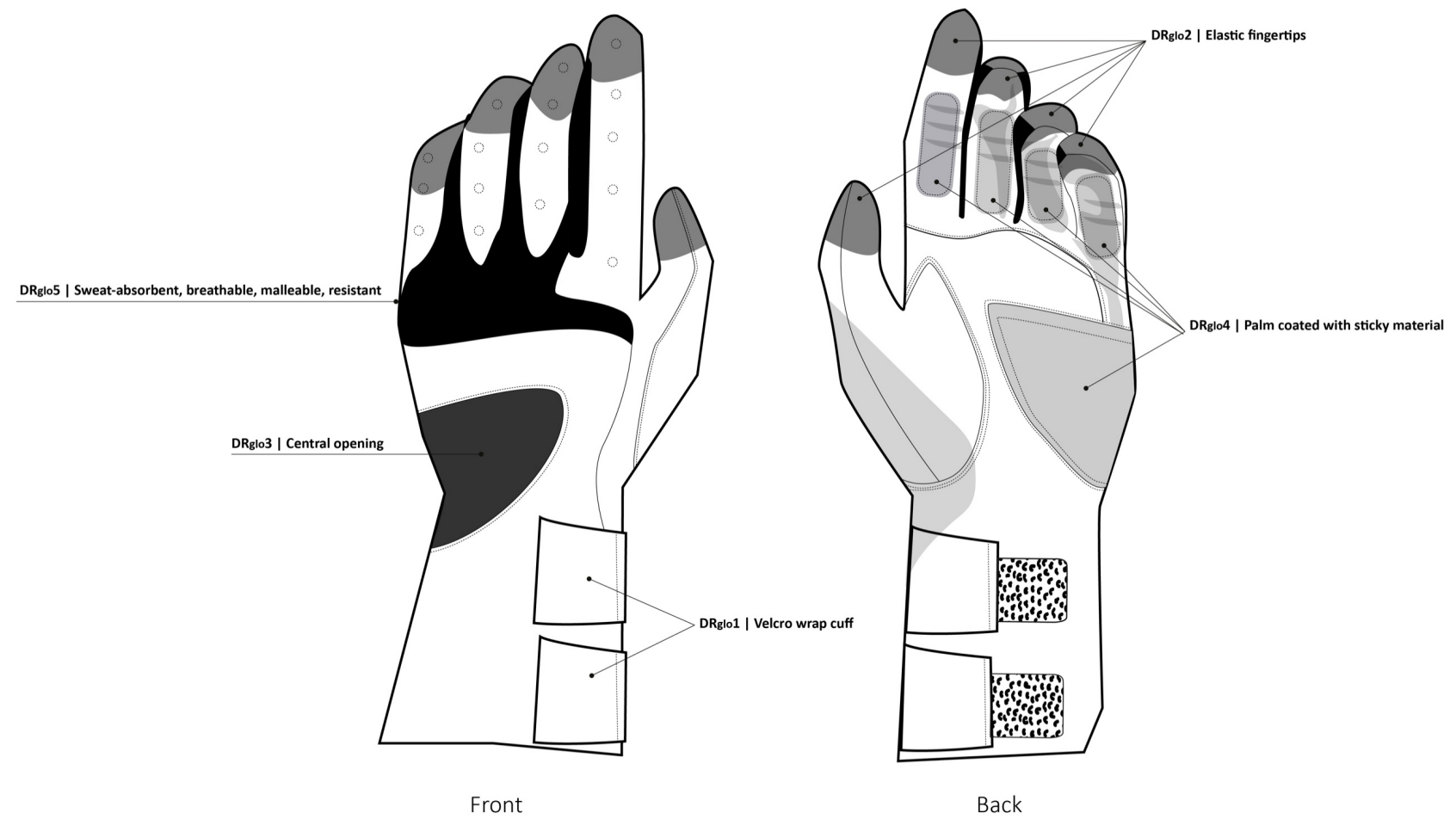

Figure 8. Summary and visual representation of the design recommendations for the gloves.

$\mathbf{D R}_{\text {glo }}$ 1| Velcro wrap cuff | One of the major problems with the gloves was that it is very difficult to secure them in place while manoeuvring the wheelchair during the game, which means that the athletes have to use tape around their wrists to secure the gloves. Having a longer cuff (ending in the middle of the forearm) that is secured with Velcro around the wrist/forearm would minimise this problem. This longer cuff would act as a continuation of the wrist, smoothly without bumps, which would in turn decrease the probability of wrist injuries. With special cuff it would be easier to attach and re-attach the Velcro around the wrists and it is most likely that some athletes would not even need assistance with this task. This would make the glove safer and more comfortable to wear. Additionally, this improvement would also reduce the costs of playing the sport as there would not be the need for the tape (which was identified as a significant source of financial costs). Another alternative for this problem would be to use a material like silicone in the inner part of the gloves to help them stay in place. However, the friction between the silicon and some surface hair could cause some pain or discomfort. Nonetheless, a thinner, lighter lining glove could be used underneath. 
$\mathbf{D R}_{\text {glo }}$ 2| Elastic fingertips | The fit of the gloves in the fingers area is seen as being of paramount importance. A solution to this problem could involve a direct elastification of the nail side of the gloves. This could be done by having gloves with fingertips made of a material with some elastic capabilities (i.e. with increased level of elastane - e.g. Lycra), would allow the gloves to stretch according to the specific user's needs, improving comfort and providing a design that could be suitable for more individuals (Voyce et al. 2008). This material would only be used to close the tips around the fingers so that the rest of the fingers are still protected with a more resistant material.

$\mathbf{D R}_{\text {glo }}$ 3| Central opening | Many athletes need assistance when putting on and taking of the gloves. Having the gloves open in the centre would make the process of putting them on and taking them off more efficient. This opening would only be visible when the gloves are not in the hand, as it would be closed with the Velcro wrap cuff mentioned in $\mathrm{DR}_{\mathrm{glo}}$ 1. This would be especially helpful for the athletes with conditions that affect their motor abilities.

$\mathrm{DR}_{\text {glo }}$ 4| Palm coated with sticky material | Every athlete needs to use rubber and/or glue to improve the grip of the gloves - without this the performance can be seriously improved. Hence, having a palm that is already coated in a sticky material would help to have a better grip and handle the ball more efficiently. This palm could be detachable (attached to the base glove with Velcro), so that it could be washed to restore its adhesive properties or replaced with a new one. This addition would cover most of the fingers and the entire palm. However, to ensure the mobility and flexibility of fingers and the hands, this added material would not be sewn together, but rather separate pieces. Silicone would be a good option for this, as it is a material that has already been used for similar applications and proved to be efficient in different moisture levels (Tomlinson et al. 2008).

DR $_{\text {glo }}$ 5 | Sweat-absorbent, breathable, malleable, resistant gloves | Hard and rigid materials affect the dexterity of the fingers and hand, compromising performance and comfort (Voyce et al. 2008). Sweat is also another factor that equates to decreased levels of performance and comfort. Hence, it would beneficial that the gloves are constructed in a sweatabsorbent, malleable, breathable material. For wicking the sweat, an absorbent layer should be on the outer part of the glove. To ensure the malleability and resistance of the gloves materials like synthetic leather (Mason et al. 2009; Tomlinson et al. 2008) allied with palm fibres could be used. Studies have shown that natural fibres used to reinforce polymeric materials offer an exceptional combination of mechanical properties that make these materials extremely resistant, almost equivalent to steel (Durowaye et al. 2014).

\section{Conclusions}

Wheelchair users require that items such as clothing and furniture have different characteristics so that they are adapted to their needs. However, this adaptation is something that does not happen very frequently, leaving this population feeling marginalised and unable to participate in certain life events.

Wheelchair rugby is a very good example of this lack of adaptation of garments to meet the end users' needs. The results of this study confirmed that there are no sports-wear available in the market for this particular sport. This fact has proven to be very dissatisfying for the athletes with disabilities that play this game. Moreover, this study highlighted the fact that gloves are a major concern for wheelchair rugby as they compromise the athletes' performance and safety. Nonetheless, tops and bottoms also presents some problems, especially in terms of fit and in the ability to regulate the core body temperature. With the results from the questionnaires and focus group conducted, it was possible to propose a set of design recommendations that are intended to be used as a basis for designers to create innovative products specific for wheelchair rugby, that take in consideration the real needs of the end-users. These design recommendations were not detailed exhaustively, as it was not the main goal of this paper and so that it gives designers freedom to be creative and further develop the product. These recommendations are intended to be used by fashion designers, so that have more information on the needs and requirements of athletes with disabilities, specifically wheelchair rugby players. This is also intended to raise awareness for the requirements of specific sports-wear equipment that promote the inclusivity of athletes with disabilities.

The ideal situation would be to have highly customised products that cater to the athletes' individual needs. However, the idea of products being tailored to individuals has some limitations in terms of who would be available to do it, as tailors usually provide a specific garment type and there are not many large manufacturers that create custom garments for specific end users. It is important to underline that, for economic reasons, it is very challenging for large manufacturers to create and develop products for small segments of the population. Nonetheless, there are still some small scale innovative producers with the skills and capabilities to produce specialised products that could be dedicated 
to these small specific segments of the population. Still, even if there are small companies willing to provide this service, the access to information about the demand is still limited. To produce items that comply with the end-users needs it is still necessary to provide suitably detailed product specifications. However, few people requiring the garments have the skills and knowledge to do this and this highlights a difficulty of the general idea of providing custom garments. There are a few small companies, usually run by people who were primarily engaged with the specialised problem/need to be addressed, that then seek to innovate and develop better products for others. The survival of such companies is endangered as costs are hard to meet due to cheaper imports and because there are fewer and fewer skilled people to produce those specialized products. The new trend seems to be outsourcing product development for specialist garments, which seriously limits the innovations and user specific input.

The design recommendations presented in this paper do not intend to portray the complete customisation of the products, they only intend to demonstrate the changes that could be introduced to the regular, said "normal", design to better adapt these products to the needs of wheelchair rugby athletes. As happens with clothing for the masses in ready-to-wear stores, where customisation depends on each individual, these design recommendations could also be used for large companies to create a clothing line that would better respond to wheelchair users' needs in general (e.g. trousers with higher rise on the back and lower rise on the front, which is an important aspect for any person adopting the sitting position for long periods of time) but in which the customisation could be further done at the individual level. The creation of collaborations and partnerships between larger manufacturers and smaller specialized companies or even individual tailors, subcontracted for the creation, development and production of these new products, would allow the existence of suitable products at relatively low costs.

This work has some inherent limitations, which researchers using this information should be aware of when interpreting the results presented in this paper. The sample size used is not very large and only represents in part the scenario for the United Kingdom - other people from other countries could have pointed out different problems and solutions. The design recommendations proposed were somewhat based on the available literature but mostly on the knowledge of the research team involved in this project. It should be noted that it is difficult to summarise in just one paper all the knowledge and experience from the research team and translate that into a small set of design recommendations.

There is still a large amount of work that needs to be done in this area so that marketable products can be created. The authors intend to further develop these recommendations and turn them into a real product. This future work will be achieved with the development of a larger project, involving people from different backgrounds (from sports to design), but most importantly, involving the real end-users, preferably athletes with disabilities that practice wheelchair rugby in different teams around the world.

\section{Acknowledgments}

The authors wish to acknowledge the commitment of the participants of this study. This study had the financial support of FCT - Fundação para a Ciência e a Tecnologia of Portugal under the projects UID/CEC/00319/2013 and UID/CTM/000264; and FEDER funds through the Competitive Factors Operational Program (COMPETE) POCI-01-0145FEDER-007136

\section{References}

Bispo, R. \& Branco, R., 2008. Designing out stigma: the role of objects in the construction of disabled people's identity. In Dare to Desire: 6th International Design and Emotion Conference.

Braganca, S. et al., 2018. Sports-Wear in Wheelchair Rugby: Establishing Design Needs. In G. Di Bucchianico \& P. F. Kercher, eds. Advances in Design for Inclusion: Proceedings of the AHFE 2017 International Conference on Design for Inclusion, July 17-21, 2017, The Westin Bonaventure Hotel, Los Angeles, California, USA. Cham: Springer International Publishing, pp. 381-389. Available at: https://doi.org/10.1007/978-3-319-60597-5_36.

Bragança, S. et al., 2016a. Effects of different body postures on anthropometric measures. In F. Rebelo \& M. Soares, eds. Advances 
in Ergonomics in Design: Proceedings of the AHFE 2016 International Conference on Ergonomics in Design, July 27-31, 2016, Walt Disney World ${ }^{\oplus}$, Florida, USA. Cham: Springer International Publishing, pp. 313-322. Available at: http://dx.doi.org/10.1007/978-3-319-41983-1_28.

Bragança, S. et al., 2016b. Implications of dynamic working postures in garments' comfort. In 6th International Ergonomics Conference (E 2016). Zadar, Croatia, pp. 31-38.

Bragança, S. et al., 2015. The impact of work clothing design on workers' comfort. In Elsevier B.V., pp. 5889-5896.

Bragança, S. et al., 2017. Work-wear pattern design to accommodate different working postures. International Journal of Clothing Science and Technology, 29(2).

Bramel, S., 2008. Key trends in sportswear design. In The Engineering of Sport 7.

Bruseberg, A. \& McDonagh-Philp, D., 2001. New product development by eliciting user experience and aspirations. International Journal of Human- ..., 55, p.435\}452. Available at: http://www.sciencedirect.com/science/article/pii/S1071581901904793.

Carrington, P., Hurst, A. \& Kane, S.K., 2014. Wearables and Chairables: Inclusive Design of Mobile Input and Output Techniques for Power Wheelchair Users. CHI '14 Proceedings of the SIGCHI Conference on Human Factors in Computing Systems, (Figure 1), pp.3103-3112. Available at: http://userpages.umbc.edu/ skane/pubs/chi14-chairables.pdf.

Carvalho, M. et al., 2015. FYT Jeans - Ergonomically designed jeans for active and sedentary lifestyles. In Fiber Society Fall 2015 Conference (FS 2015). Raleigh, North Carolina, USA.

Carvalho, M. et al., 2009. WeAdapt: Inclusive clothing design proposal for product development. In Include 2009.

Chang, W.-M. et al., 2009. Design and Study of Clothing Structure for People with Limb Disabilities. Journal of Fiber Bioengineering and Informatics, 2(1), pp.62-67.

Chua, J., 2013. A novel approach to identify and quantify activity and performance in wheelchair rugby. PhD, (May).

Churton, E. \& Keogh, J.W., 2013. Constraints influencing sports wheelchair propulsion performance and injury risk. Sports Medicine, Arthroscopy, Rehabilitation, Therapy \& Technology, 5(1), p.3. Available at: http://bmcsportsscimedrehabil.biomedcentral.com/articles/10.1186/2052-1847-5-3.

Çivitci, Ş., 2004. An ergonomic garment design for elderly Turkish men. Applied Ergonomics, 35(3), pp.243-251.

Clulow, E.E., 1974. Clothes for the handicapped. The Journal of the Royal College of General Practitioners, 24(142), pp.362-6.

Curteza, A. et al., 2014. Designing Functional Clothes for Persons with Locomotor Disabilities. Autex Research Journal, 14(4), pp.281289.

Durowaye, S.I. et al., 2014. Mechanical Properties of Particulate Coconut Shell and Palm Fruit Polyester Composites. Progress in Polymer Science, 4(4), pp.141-147.

Elliott, G.C. et al., 1982. Understanding stigma: Dimensions of deviance and coping. Deviant behavior, 3(3), pp.275-300.

Fowler, D., 1999. The Attributes Sought in Sports Apparel: A Ranking. Journal of Marketing Theory and Practice, 7(4), pp.81-88. Available at: http://www.tandfonline.com.zorac.aub.aau.dk/doi/abs/10.1080/10696679.1999.11501853.

Gill, S. \& Prendergast, J., 2015. Garment Fit and Consumer Perception of Sportswear. Materials and Technology for Sportswear and Performance Apparel, pp.245-260. Available at: http://dx.doi.org/10.1201/b19359-11.

Gonzalez, J.C. et al., 2012. FASHION-ABLE: Needs and requirements for clothing, footwear and orthotics of consumers groups with highly individualised needs. 2012 18th International Conference on Engineering, Technology and Innovation, ICE 2012 Conference Proceedings, pp.1-10.

Hernández, N., 2000. Tailoring the unique figure.

Hignett, S., 2013. Why design starts with people. Health Foundation, (May), pp.1-5. Available at: http://patientsafety.health.org.uk/sites/default/files/resources/why_design_starts_with_people.pdf.

Howe, I., 2012. Fashioning Identity : Inclusive Clothing Design and Spinal Cord Injury. University of Sydney.

IWRF, 2017. International Wheelchair Rugby Federation - Gloves in wheelchair rugby.

IWRF, 2015. International Wheelchair Rugby Federation - International Rules for the Sport of Wheelchair Rugby. , (January), pp.1-44.

Kabel, A., Dimka, J. \& McBee-Black, K., 2017. Clothing-related barriers experienced by people with mobility disabilities and impairments. Applied Ergonomics, 59, pp.165-169. Available at: http://dx.doi.org/10.1016/j.apergo.2016.08.036.

Kell, P., Kell, M. \& Price, N., 2008. Two games and one movement? The Paralympics and the Olympic movement. Tennis, p.236.

Kim, S. et al., 2008. Mechanical properties of polypropylene / natural fiber composites : Comparison of wood fiber and cotton fiber. , 27, pp.801-806.

Kozey, J.W. \& Das, B., 2004. Determination of the normal and maximum reach measures of adult wheelchair users. International Journal of Industrial Ergonomics, 33(3), pp.205-213.

Kratz, G. et al., 1997. Wheelchair users' experience of non-adapted and adapted clothes during sailing, quad rugby or wheel-walking. Disability And Rehabilitation, 19(1), pp.26-34. Available at: http://search.ebscohost.com/login.aspx?direct=true \&db=cmedm\&AN=9021282\&site=ehost-live.

Lucero-Duarte, K. et al., 2012. Anthropometric data of adult wheelchair users for Mexican population. Work (Reading, Mass.), 41 Suppl 1(SUPPL.1), pp.5408-10.

Lutgendorf, M. et al., 2009. The effect of glove type on wheelchair rugby sports performance. Assistive Technology Research Series, 26(3), pp.363-365.

Mason, B.S., van der Woude, L.H.V. \& Goosey-Tolfrey, V.L., 2009. Influence of Glove Type on Mobility Performance for Wheelchair Rugby Players. American Journal of Physical Medicine \& Rehabilitation, 88(7), pp.559-570. Available at: http://content.wkhealth.com/linkback/openurl?sid=WKPTLP:landingpage\&an=00002060-200907000-00006.

McCann, J., 2008. Material requirements for the design of performance sportswear. In The Engineering of Sport 7.

Özdil, N. \& Anand, S., 2014. Recent Developments in Textile Materials and Products Used for Activewear Spor ve Aktif Giyimde Kullanılan Tekstil Malzeme ve Ürünlerinde Son Gelişmeler. , 2014(3), pp.68-83.

Pullin, G., 2009. Design meets diability, Cambridge, Massachusetts: MIT Press.

Sasaki, M. et al., 2008. Simulator for optimal wheelchair design. Journal of Robotics and Mechatronics, 20(6), p.854.

Shim, S. \& Bickle, M.C., 1994. Benefit segments of the female apparel market: Psychographics, shopping orientations, and 
demographics. Clothing and Textiles Research Journal, 12(2), pp.1-12.

Shinohara, K. \& Wobbrock, J.O., 2011. In the shadow of misperception: assistive technology use and social interactions. In Proceedings of the SIGCHI Conference on Human Factors in Computing Systems. ACM, pp. 705-714.

Sionkowska, A., 2011. Current research on the blends of natural and synthetic polymers as new biomaterials : Review. Progress in Polymer Science, 36, pp.1254-1276.

Thorén, M., 1996. Systems approach to clothing for disabled users. Why is it difficult for disabled users to find suitable clothing. Applied Ergonomics, 27(6), pp.389-396.

Tomlinson, S.E., Lewis, R. \& Carré, M.J., 2008. Friction between Players' Hands and Sports Equipment (P7). In The Engineering of Sport 7. Springer, pp. 27-34.

Usma-Alvarez, C.C. et al., 2010. Identification of design requirements for rugby wheelchairs using the QFD method. Procedia Engineering, 2(2), pp.2749-2755. Available at: https://www.scopus.com/inward/record.uri?eid=2-s2.078149315665\&partnerID=40\&md5=7fa22758e0597fceca6b32c731b27d8c.

Voyce, J., Dafniotis, P. \& Towlson, S., 2008. Elastic textiles. In The Engineering of Sport 7.

Wang, Y. et al., 2014. Evaluation on an ergonomic design of functional clothing for wheelchair users. Applied Ergonomics, 45(3), pp.550-555.

Wu, D.W., Wang, Y.Y. \& Li, J., 2011. Design of Functional Daily Wear for Wheelchair Users. Advanced Materials Research, 332-334, pp.458-461.

Wu, S.K. \& Williams, T., 2001. Factors influencing sport participation among athletes with spinal cord injury. Medicine \& Science in Sports \& Exercise, 33(2), pp.177-182. 


\section{Appendix 1. Focus group introduction and questions}

\section{Introduction}

Welcome! Thanks for agreeing to be part of the focus group. I appreciate your willingness to participate.

My name is [name of the moderator] and I am I postdoctoral researcher here. We are doing a project on wheelchair rugby and our idea is to develop a garment, specific for this sport that allows the player to feel more comfortable and safe and also to improve their performance.

As such, I am conducting this focus group to understand your opinions about the clothes that you usually wear during training and games. Your inputs are very important so that we can develop something that responds to you needs and desires. So we want you to share your honest and open thoughts with me.

So now, let's establish some "rules":

1. We want you to do the talking. | We would like everyone to participate.

2. There are no right or wrong answers. | Every person's experiences and opinions are important. | Speak up whether you agree or disagree. | We want to hear a wide range of opinions.

3. We will be video recording the group. | We want to capture everything you have to say. | We don't identify anyone by name in our report. You will remain anonymous. I I am going to hand you a consent form for you to sign if you agree with the terms.

\section{Questions}

1. What are your thoughts about the items of sports clothing that you normally wear?

2. Would you say you are satisfied with the current situation?

3. What are the things you are dissatisfied with?

4. What would you like to see changed? How should it be changed? What kinds of things would you like to see happen?

5. When you go to buy new the items of sports clothing what are the key features that make you choose one item over another one?

6. What do you value the most? Safety? Comfort? Functionality? Performance?

7. How about the restricted imposed by the clothes? What do you think about that?

8. Are the clothes restricting your movements? Are they influencing your performance?

9. How about the fabric used? Do you like them? Do you think that they influence you comfort and/or performance?

10. How about some wearable technologies? Would you be interested on that?

11. What would be the most valuable thing to add? Should it be used to monitor safety or performance? Or both?

12. Would you be interested in paying more for bespoke items?

13. Are there other recommendations that you have, or suggestions you would like to make?

14. Are there other things you would like to say before we wind up? 


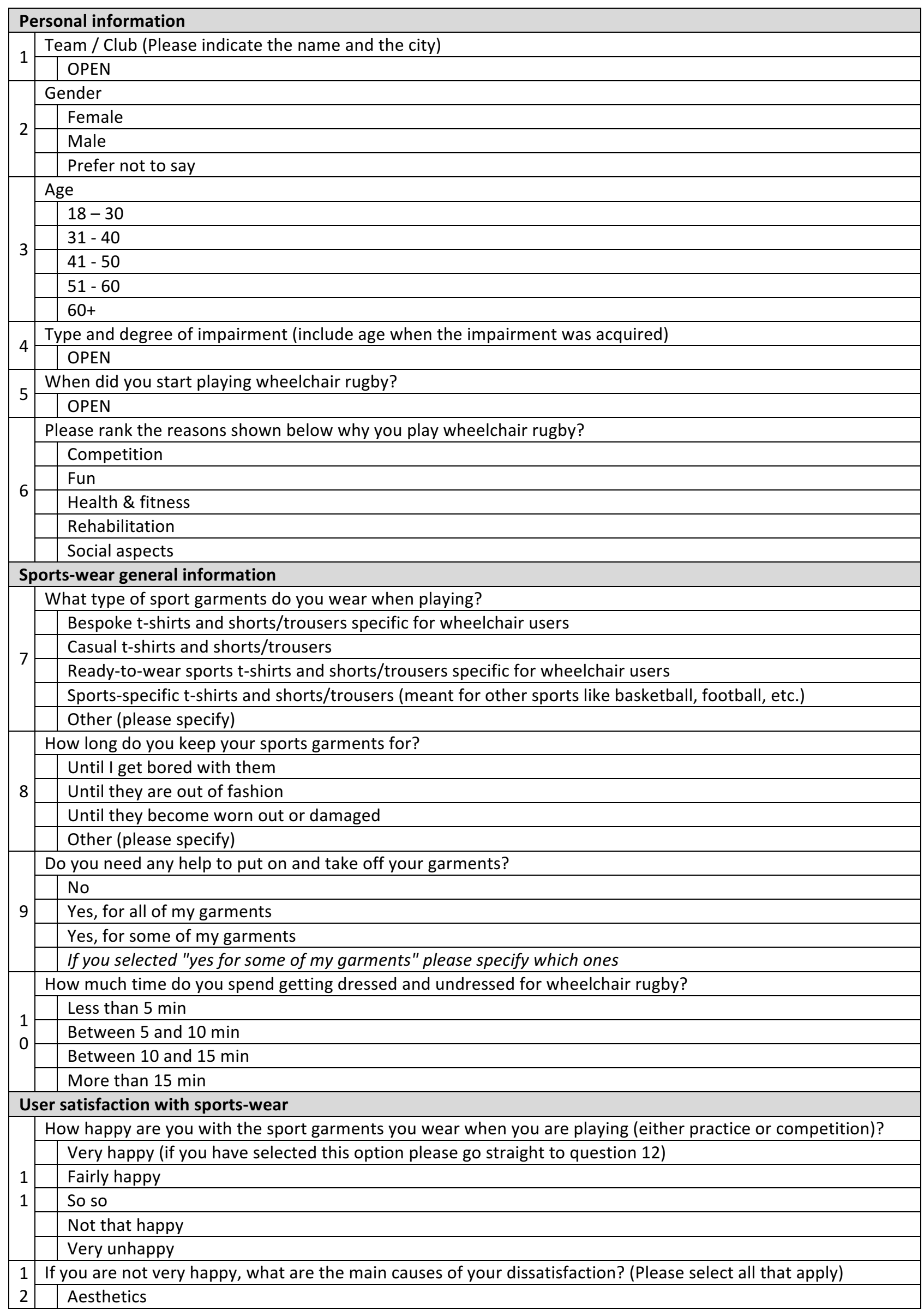




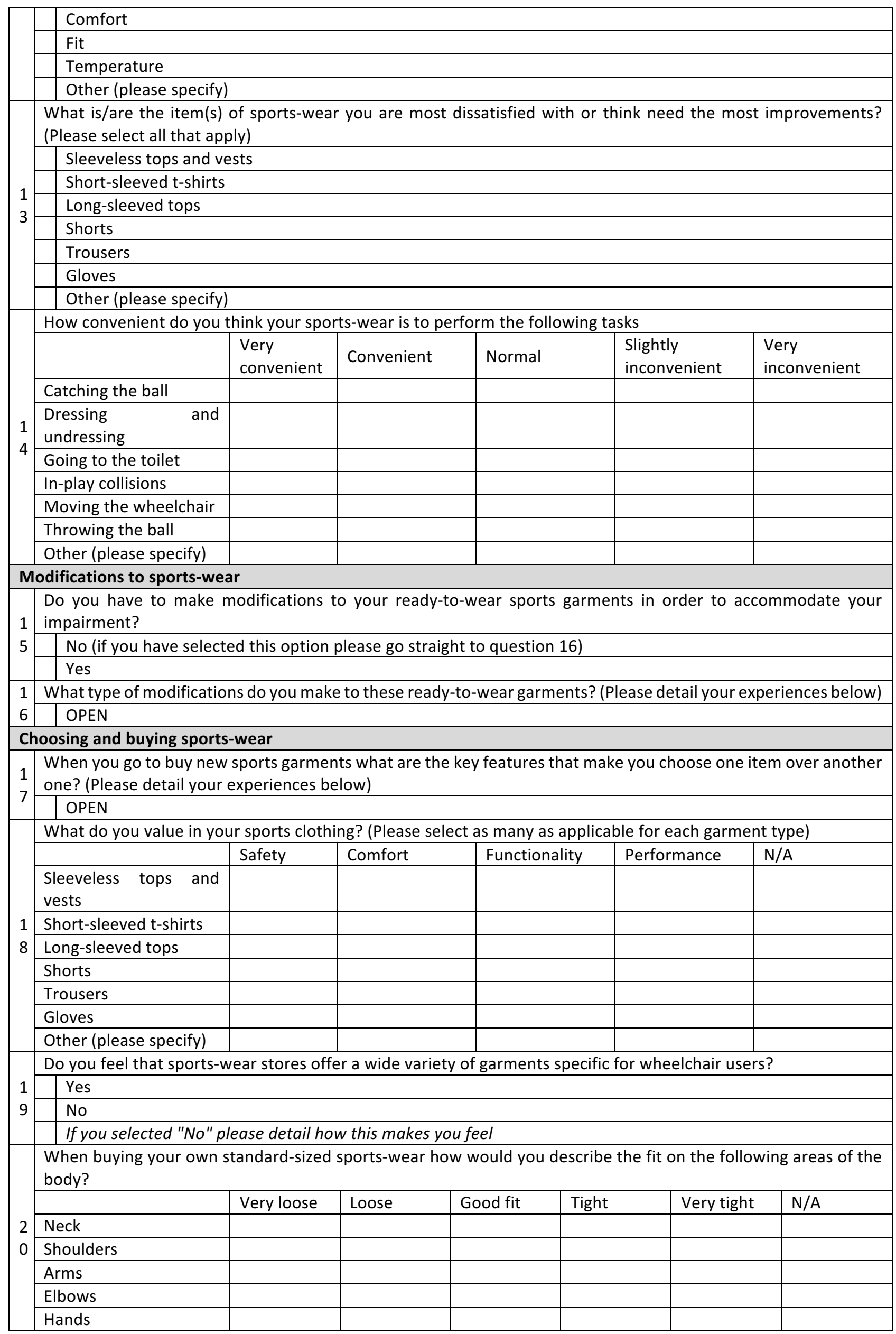




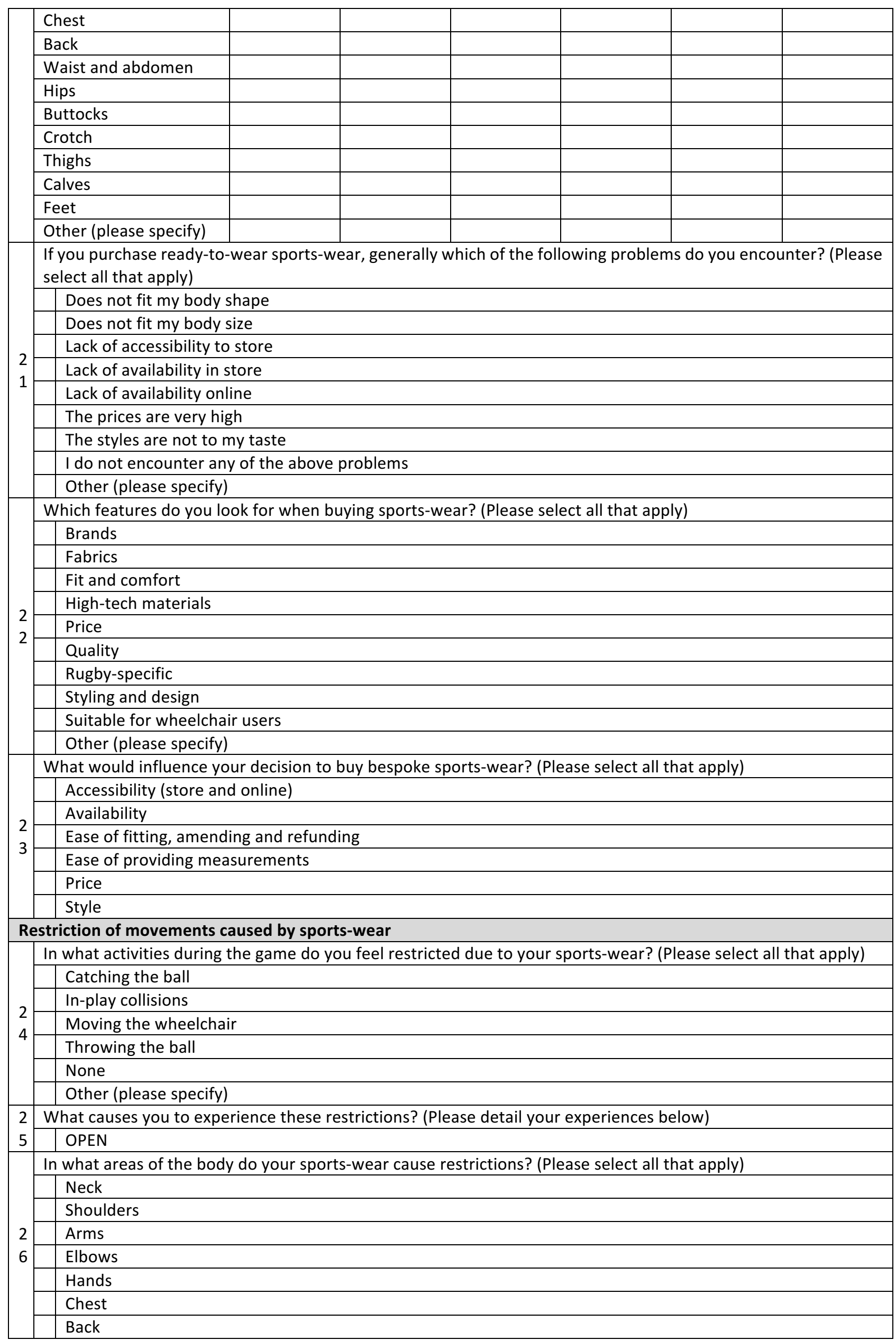




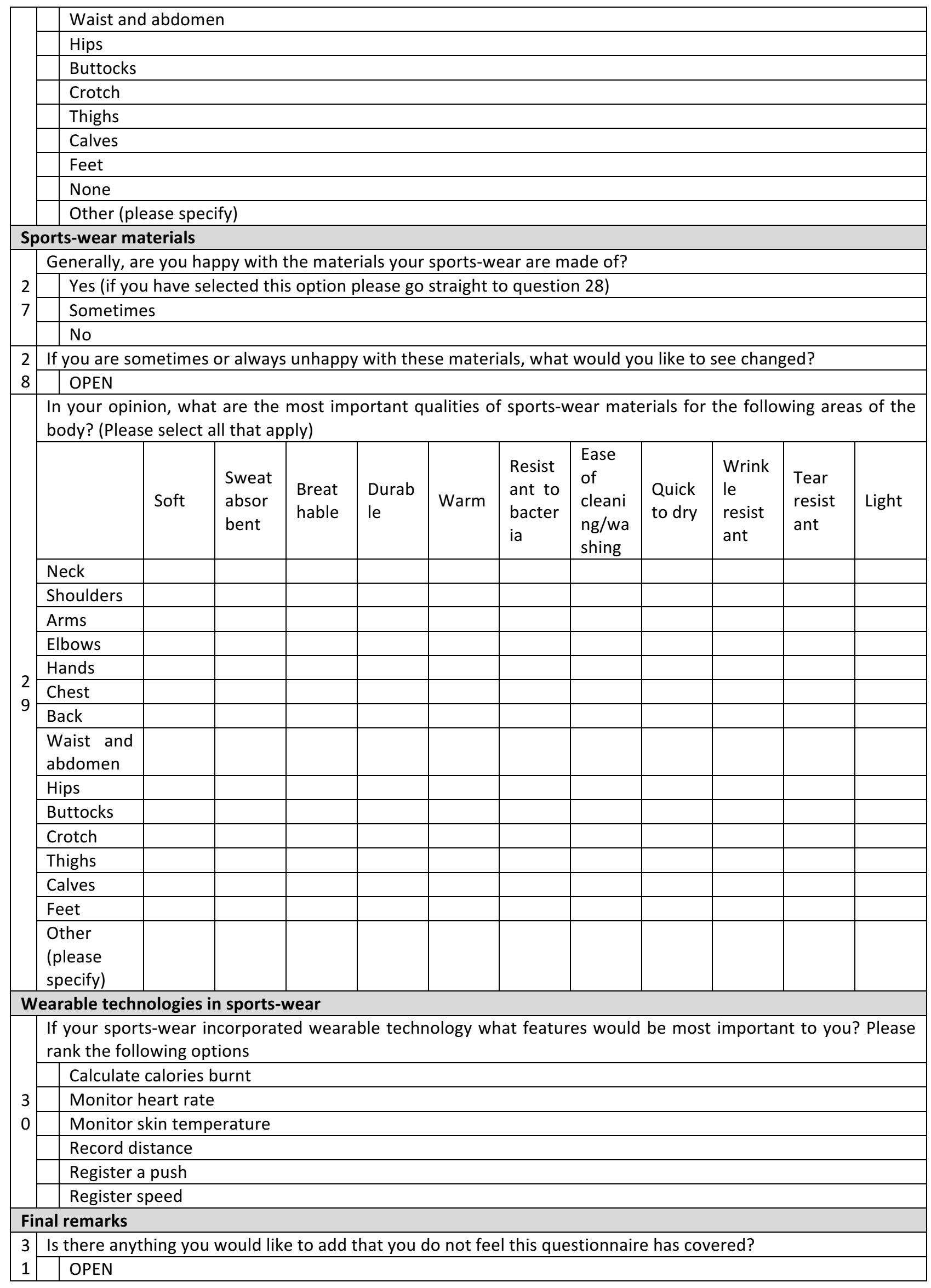

